\title{
Evidence of $\mathrm{Cu}$ Separation in Lithiated $\mathrm{Cu}_{6} \mathrm{Sn}_{5}$
}

\section{Lithium-Ion Battery Anodes}

Xin F. Tan ${ }^{a,}$, , Wenhui Yang ${ }^{b}$, Kohei Aso $^{b}$, Syo Matsumura ${ }^{b}$, Stuart D. McDonald ${ }^{a}$, Kazuhiro

$$
\text { Nogita }^{a}
$$

${ }^{a}$ Nihon Superior Centre for the Manufacture of Electronic Materials (NS CMEM), School of Mechanical and Mining Engineering, The University of Queensland, St. Lucia, Brisbane, Queensland 4072, Australia

${ }^{\mathrm{b}}$ Department of Applied Quantum Physics and Nuclear Engineering, Kyushu University, Fukuoka 819-0395, Japan

*Tel: +61-4-3206-5458. Fax: +61-7-3365-4799. E-mail: xin.tan@uq.edu.au. 


\section{Appendix A. Sample fabrication and experimental methods}

A Sn- $0.7 \mathrm{wt} \% \mathrm{Cu}$ alloy sheet of thickness between 50 to $100 \mu \mathrm{m}$ was placed on top of a $9 \mu \mathrm{m}$ thick $\mathrm{Cu}$ current collector with surface oxides removed using a soldering flux (Pacweld 62). The sheets were clamped between two glass slides and left at $232^{\circ} \mathrm{C}$ in an annealing oven for 1 hour. The Sn liquefied at this temperature and the reaction between $\mathrm{Sn}$ and $\mathrm{Cu}$ proceeded spontaneously to form $\mathrm{Cu}_{6} \mathrm{Sn}_{5}$ intermetallic compounds (IMCs) at the melt-solid interface (Figure 1a). The sandwich was then cooled to room temperature in air. Excess Sn was removed by chemical dissolution in a solution of $1.75 \mathrm{~g}$ ortho-nitrophenol and $2.5 \mathrm{~g}$ sodium hydroxide in $50 \mathrm{ml}$ distilled water at $80^{\circ} \mathrm{C}$ for 90 minutes, and the electrode was subsequently rinsed with ethanol. Following this, the electrode was dried in a vacuum chamber for 2 hours. The dried electrode and a piece of blank $\mathrm{Cu}$ foil were weighed to an accuracy of $0.1 \mathrm{mg}$ to determine the Sn loading on the sample.

The electrode was assembled into a coin cell with $\mathrm{Li}$ foil as a counter electrode, $1 \mathrm{M} \mathrm{LiPF}_{6}$ in ethylene carbonate/dimethyl carbonate (EC/DMC) 50:50 as an electrolyte and Celgard ${ }^{\circledR}$ as a separator. The coin cell was then discharged to $0.02 \mathrm{~V}$ with a low discharge current of 0.03 $\mathrm{mA} \mathrm{cm}{ }^{-2}$ in a battery tester.

The coin cell was disassembled and the lithiated powders were scraped from the surface of the electrode and dispersed in alcohol by sonication in a water bath. A drop of the solution was deposited onto a Si chip and the chip was dried overnight in a vacuum chamber. A powder particle (Figure 1b) was welded on to the Si chip by Pt deposition, and then cut into a TEM lamellar with a focused ion beam (FIB) on a FEI SCIOS DualBeam FIB/SEM system to produce a sample with even thickness which can facilitate interpretation of the image contrast under TEM. Pt deposition is performed by first depositing two pillars of Pt on either side of the powder particle (PtDep1 and PtDep2 areas shown in Figure S.1) to weld the particle on to the 
Si chip. The two pillars are of similar height to the powder particle $(\sim 6 \mu \mathrm{m})$ to facilitate the subsequent deposition of a final Pt strip which protects the sample from direct exposure to the ion beam, indicated by the PtDep3 area shown in Figure S.1. All Pt depositions are performed at a current density of $6 \mathrm{pA} \mu \mathrm{m}^{-2}$. The TEM lamellar was welded on to a Si TEM half grid before thinning to thicknesses transparent to electrons (Figure 1c). Low Ga ion beam currents and voltages, as shown in Table S.1, were used during thinning of the lamellar below $1 \mu \mathrm{m}$ lamellar thickness, to minimise the stripping of Li from the electrode material.

Due to lithiation by alloying, the lithiated compounds of $\mathrm{Cu}_{6} \mathrm{Sn}_{5}$, including the $\mathrm{Li}_{\mathrm{x}} \mathrm{Cu}_{6} \mathrm{Sn}_{5}$ and the $\mathrm{Li}_{(13+y)} \mathrm{Sn}_{5}$ phases are relatively stable in air as the standard Gibbs free energy change, $\Delta \mathrm{G}^{0}$, in the oxidation reactions of these phases are more positive (calculations based on the formation energies of $\mathrm{Li}_{(13+\mathrm{y})} \mathrm{Sn}_{5}$ [1] and $\mathrm{Li}_{2} \mathrm{O}$ are presented in Appendix A.1), which allows TEM sample preparation and sample transfer in atmospheric conditions.

SAED, imaging and EDS observations were performed on the TEM lamellar sample on a JEOL JEM-ARM200F TEM at an accelerating voltage of $200 \mathrm{kV}$, while the EELS study was performed on a JEOL JEM-ARM200CF TEM at an accelerating voltage of $120 \mathrm{kV}$. The EELS energy resolution is calibrated to $0.5 \mathrm{eV}$ based on the measurement of the full width at half maximum (FWHM) of the zero loss peak. The SAED pattern obtained was analysed with DiffTools [2], while the EELS data was processed by DigitalMicrograph EELS. 

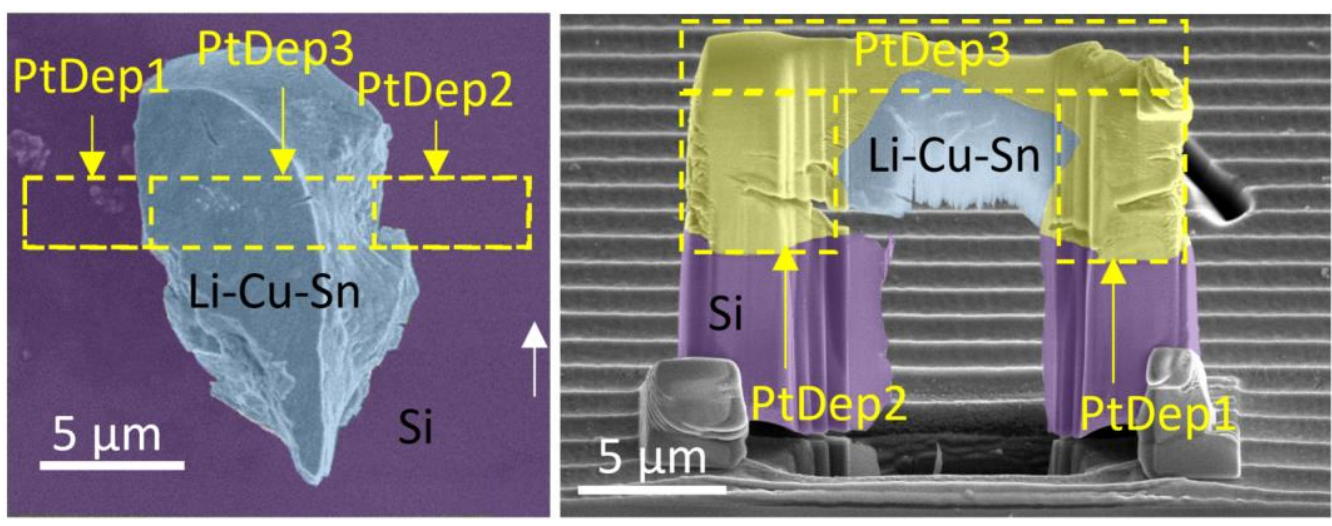

Figure S.1. PtDep1, PtDep2 and PtDep3 areas on the powder, and the corresponding areas in the thinned TEM lamellar.

Table S.1. Ga ion beam voltages and currents at different lamellar thicknesses.

\begin{tabular}{|c|c|c|}
\hline $\begin{array}{c}\text { Lamellar thickness, } \\
\mathrm{nm}\end{array}$ & $\begin{array}{c}\text { Ga ion beam voltage, } \\
\mathrm{kV}\end{array}$ & Ga ion beam current \\
\hline $1,000-700$ & 30 & $0.5 \mathrm{nA}$ \\
\hline $700-300$ & 30 & $0.3 \mathrm{nA}$ \\
\hline $300-100$ & 30 & $0.1 \mathrm{nA}$ \\
\hline Final thinning & 5,2 & $78,30 \mu \mathrm{A}$ \\
\hline
\end{tabular}




\section{Appendix A.1. Calculations for standard Gibbs free energy changes in oxidation reactions of $\mathrm{Li}, \mathrm{Li}_{13} \mathrm{Sn}_{5}$ and $\mathrm{Li}_{22} \mathrm{Sn}_{5}$.}

The standard Gibbs free energy change for a reaction, $\Delta \mathrm{G}^{0}=\Sigma \mathrm{n} \Delta \mathrm{G}_{\mathrm{f} \text {, products }}^{0}-\Sigma \mathrm{m} \Delta \mathrm{G}_{\mathrm{f}}^{0}$, reactants, where $\mathrm{n}$ and $\mathrm{m}$ are the coefficients in the balanced chemical equation of the reaction, while $\Delta \mathrm{G}_{\mathrm{f} \text {, products }}^{0}$ and $\Delta \mathrm{G}_{\mathrm{f} \text {, reactants }}^{0}$ are the formation energies of the products and the reactants respectively.

The oxidation reaction of $\mathrm{Li}$ to create 1 mole of $\mathrm{Li}_{2} \mathrm{O}$ is given below:

$$
2 \mathrm{Li}+\frac{1}{2} \mathrm{O}_{2} \rightarrow \mathrm{Li}_{2} \mathrm{O} \quad \text { Eq. (A.1) }
$$

$\Delta \mathrm{G}^{0}(\mathrm{Li})=[(1 \mathrm{x}-142.9 \mathrm{~kJ} / \mathrm{mol})]-[(2 \times 0 \mathrm{~kJ} / \mathrm{mol})+(1 / 2 \times 0 \mathrm{~kJ} / \mathrm{mol})]=-142.9 \mathrm{~kJ} / \mathrm{mol}$

The oxidation reaction of $\mathrm{Li}_{13} \mathrm{Sn}_{5}$ to create 1 mole of $\mathrm{Li}_{2} \mathrm{O}$ is given below:

$$
\frac{2}{13} \mathrm{Li}_{13} \mathrm{Sn}_{5}+\frac{1}{2} \mathrm{O}_{2} \rightarrow \mathrm{Li}_{2} \mathrm{O}+\frac{10}{13} \mathrm{Sn} \quad \text { Eq. (A.2) }
$$

The formation energy of $\mathrm{Li}_{13} \mathrm{Sn}_{5}$ is $-0.42 \mathrm{eV} /$ atom [1], which is equivalent to $-729.4 \mathrm{~kJ} / \mathrm{mol}$ of $\mathrm{Li}_{13} \mathrm{Sn}_{5}$ molecules.

$$
\Delta \mathrm{G}^{0}\left(\mathrm{Li}_{13} \mathrm{Sn}_{5}\right)=[(1 \mathrm{x}-142.9 \mathrm{~kJ} / \mathrm{mol})+(10 / 13 \mathrm{x} 0 \mathrm{~kJ} / \mathrm{mol})]-[(2 / 13 \mathrm{x}-729.4 \mathrm{~kJ} / \mathrm{mol})+(1 / 2 \mathrm{x}
$$

$0 \mathrm{~kJ} / \mathrm{mol})]=-30.7 \mathrm{~kJ} / \mathrm{mol}$

The oxidation reaction of $\mathrm{Li}_{22} \mathrm{Sn}_{5}$ to create 1 mole of $\mathrm{Li}_{2} \mathrm{O}$ is given below:

$$
\frac{2}{22} \mathrm{Li}_{22} \mathrm{Sn}_{5}+\frac{1}{2} \mathrm{O}_{2} \rightarrow \mathrm{Li}_{2} \mathrm{O}+\frac{10}{22} \mathrm{Sn} \quad \text { Eq. (A.3) }
$$

The formation energy of $\mathrm{Li}_{22} \mathrm{Sn}_{5}$ is $-0.30 \mathrm{eV} /$ atom [1], which is equivalent to $-781.5 \mathrm{~kJ} / \mathrm{mol}$ of $\mathrm{Li}_{22} \mathrm{Sn}_{5}$ molecules. 
$\Delta \mathrm{G}^{0}\left(\mathrm{Li}_{22} \mathrm{Sn}_{5}\right)=[(1 \mathrm{x}-142.9 \mathrm{~kJ} / \mathrm{mol})+(10 / 22 \times 0 \mathrm{~kJ} / \mathrm{mol})]-[(2 / 22 \mathrm{x}-781.5 \mathrm{~kJ} / \mathrm{mol})+(1 / 2 \mathrm{x}$

$0 \mathrm{~kJ} / \mathrm{mol})]=-71.9 \mathrm{~kJ} / \mathrm{mol}$

Therefore the oxidation of $\mathrm{Li}$ is more spontaneous than that of $\mathrm{Li}_{22} \mathrm{Sn}_{5}$, which is in turn more spontaneous than that of $\mathrm{Li}_{13} \mathrm{Sn}_{5}$. 


\section{Appendix B. Annular dark field contrast}

Contrast in TEM is often a combination of mass-thickness contrast and Bragg diffraction contrast. FIB samples can largely eliminate the contrast arising from variations in sample thickness, while at high scattering angles $\left(>5^{\circ}\right)$ in the cases of annular dark field (ADF) STEM, Bragg scattering is usually negligible, and contrast in the image is mainly due to variations in Q, the total elastic scattering cross-section, in each phase [3].

$$
Q=\frac{N_{0} \sigma \rho}{A}
$$

where $N_{0}$ is Avogradro's number, $\sigma$ is the single atom scattering cross-section, $\rho$ is the density, and $A$ is the atomic weight of each phase. For high scattering angles, $\sigma$ is proportional to $Z^{2}$. As a result,

$$
Q \propto \frac{Z^{2} \rho}{A}
$$

and all three variables are properties of the phases in the sample, free from influence from thickness variation or Bragg diffraction. 


\section{Appendix C. Strategies to inhibit the diffusion of $\mathrm{Cu}$}

To inhibit the separation of $\mathrm{Cu}$ from the $\mathrm{Li}-\mathrm{Sn}$ compounds, early works on $\mathrm{Cu}_{6} \mathrm{Sn}_{5}$ have suggested to operate the electrode above $0.2 \mathrm{~V}$ to avoid the second lithiation reaction $[4,5]$. However, this method sacrifices the capacity of the anodes. Recently, it was found doping $\mathrm{Cu}_{6} \mathrm{Sn}_{5}$ anodes with $\mathrm{Ni}$ can result in the formation of $(\mathrm{Cu}, \mathrm{Ni})_{6} \mathrm{Sn}_{5}$ with partially blocked diffusion channels which retards the second lithiation reaction even when the electrode is lithiated to $0.02 \mathrm{~V}$ [6]. Since $\mathrm{Cu}$ atoms (atomic radius $128 \mathrm{pm}$ ) are larger than $\mathrm{Li}$-ions (ionic radius $76 \mathrm{pm}$ ), tailoring the crystal structures to allow the diffusion of Li-ions while impeding the diffusion of $\mathrm{Cu}$ may be an effective strategy which does not sacrifice the anode capacity. Furthermore, nanostructuring is often found to improve the cyclic stability of intermetallic anodes [7, 8]. On top of better stress relief properties [9], it is possible that nanostructuring also has the advantage of limiting the diffusion range of $\mathrm{Cu}$ to within the nanostructure, and thereby improving the reaction kinetics and the reversibility of reaction 2. 


\section{Appendix D. Improving the cyclic stability of $\mathrm{Cu}_{6} \mathrm{Sn}_{5}$ anodes}

Nanostructuring the anode can significantly improve the cyclic stability as there is less stress accumulation [7-9]. Research has also attributed the poor cyclic stability to the incompatibility of the electrolytes, which are primarily developed for carbon-based anodes, and this results in instability in the SEI [10]. There have been some efforts to counter this problem by mixing or coating Sn-based anodes with carbon to form stable SEIs and stability up to a several hundred cycles has been demonstrated [11-13]. Finding an electrolyte additive which acts on Sn-based anodes similarly to fluoroethylene carbonate (FEC) in the electrolytes used to improve the cyclic stability of Si-based anodes [14] may also solve this problem. 


\section{References}

[1] Mayo, M. and Morris, A.J., Structure Prediction of Li-Sn and Li-Sb Intermetallics for Lithium-Ion Batteries Anodes. Chemistry of Materials, 2017. 29(14): p. 5787-5795, DOI: 10.1021/acs.chemmater.6b04914.

[2] Mitchell, D.R., DiffTools: electron diffraction software tools for DigitalMicrograph. Microsc Res Tech, 2008. 71(8): p. 588-93, DOI: 10.1002/jemt.20591.

[3] Williams, D.B. and Carter, C.B., Transmission Electron Microscopy: A Textbook for Materials Science. Second ed. 2009: Springer, 978-0-387-76501-3.

[4] Kepler, K.D., $\mathrm{Li}_{x} \mathrm{Cu}_{6} \mathrm{Sn}_{5}(0<x<13)$ : An Intermetallic Insertion Electrode for Rechargeable Lithium Batteries. Electrochemical and Solid-State Letters, 1999. 2(7): p. 307, DOI: $10.1149 / 1.1390819$.

[5] Kepler, K.D., Vaughey, J.T. and Thackeray, M.M., Copper-tin anodes for rechargeable lithium batteries: an example of the matrix effect in an intermetallic system. Journal of Power Sources, 1999. 81-82: p. 383-387, DOI: 10.1016/s0378-7753(99)00111-1.

[6] Tan, X.F., Mcdonald, S.D., Gu, Q., Wang, L., Matsumura, S. and Nogita, K., The effects of $\mathrm{Ni}$ on inhibiting the separation of $\mathrm{Cu}$ during the lithiation of $\mathrm{Cu}_{6} \mathrm{Sn}_{5}$ lithium-ion battery anodes. Journal of Power Sources, 2019. 440: p. 227085, DOI: 10.1016/j.jpowsour.2019.227085.

[7] Wolfenstine, J., Campos, S., Foster, D., Read, J. and Behl, W.K., Nano-scale Cu6Sn anodes. Journal of Power Sources, 2002. 109(1): p. 230-233, DOI: 10.1016/S03787753(02)00061-7.

[8] Han, Q.G., Yi, Z., Cheng, Y., Wu, Y.M. and Wang, L.M., Simple preparation of $\mathrm{Cu}_{6} \mathrm{Sn}_{5} / \mathrm{Sn}$ composites as anode materials for lithium-ion batteries. Rsc Advances, 2016. 6(19): p. 15279-15285, DOI: 10.1039/c5ra23788b.

[9] Kamali, A.R. and Fray, D.J., Tin-Based Materials as Advanced Anode Materials for Lithium Ion Batteries: A Review. Reviews on Advanced Materials Science, 2011. 27(1): p. 1424.

[10] Sengupta, S., Mitra, A., Dahiya, P.P., Kumar, A., Mallik, M., Das, K., Majumder, S.B. and Das, S., Investigation on lithium conversion behavior and degradation mechanisms in Tin based ternary component alloy anodes for lithium ion batteries. Journal of Alloys and Compounds, 2017. 721: p. 236-248, DOI: 10.1016/j.jallcom.2017.06.005.

[11] Thorne, J.S., Dahn, J.R., Obrovac, M.N. and Dunlap, R.A., An In Situ Study of the Electrochemical Reaction of Li with Amorphous/Nanostructured Cu6 $\mathrm{Sn}_{5}+C$. Journal of The Electrochemical Society, 2011. 158(12): p. A1328, DOI: 10.1149/2.040112jes.

[12] Hu, R., Waller, G.H., Wang, Y., Chen, Y., Yang, C., Zhou, W., Zhu, M. and Liu, M., $\mathrm{Cu}_{6} \mathrm{Sn}_{5} @ \mathrm{SnO}_{2}-\mathrm{C}$ nanocomposite with stable core/shell structure as a high reversible anode for Li-ion batteries. Nano Energy, 2015. 18: p. 232-244, DOI: 10.1016/j.nanoen.2015.10.037.

[13] Peng, H., Li, R., Hu, J., Deng, W. and Pan, F., Core-Shell Sn-Ni-Cu-Alloy@Carbon Nanorods to Array as Three-Dimensional Anode by Nanoelectrodeposition for High- 
Performance Lithium Ion Batteries. ACS Appl Mater Interfaces, 2016. 8(19): p. 12221-7, DOI: 10.1021/acsami.6b03383.

[14] Hou, T., Yang, G., Rajput, N.N., Self, J., Park, S.-W., Nanda, J. and Persson, K.A., The influence of FEC on the solvation structure and reduction reaction of LiPF $6 / E C$ electrolytes and its implication for solid electrolyte interphase formation. Nano Energy, 2019. 64: p. 103881, DOI: 10.1016/j.nanoen.2019.103881. 